\title{
GEM/POPs: a global 3-D dynamic model for semi-volatile persistent organic pollutants - Part 1: Model description and evaluations of air concentrations
}

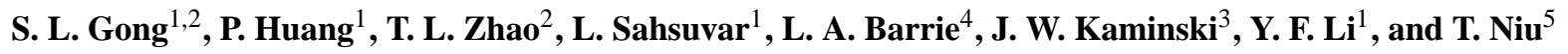 \\ ${ }^{1}$ Air Quality Research Division, Science \& Technology Branch, Environment Canada, 4905 Dufferin Street, Toronto, Ontario \\ M3H 5T4, Canada \\ ${ }^{2}$ Department of Chemical Engineering and Applied Chemistry, University of Toronto, 200 College Street, Toronto, Ontario, \\ Canada, M5S 3E5, Canada \\ ${ }^{3}$ Department of Earth and Space Science and Engineering, York University, 4700 Keele Street, Toronto, Ontario, M3J 1P3, \\ Canada \\ ${ }^{4}$ Atmospheric Research and Environment Program, World Meteorological Organization, 7 bis, avenue de la Paix, BP2300, \\ 1211 Geneva 2, Switzerland \\ ${ }^{5}$ Certre for Atmosphere Watch \& Services (CAWAS), Chinese Academy of Meteorological Sciences, China Meteorological \\ Administration (CMA), Beijing 100081, China
}

Received: 19 January 2007 - Published in Atmos. Chem. Phys. Discuss.: 2 March 2007

Revised: 30 May 2007 - Accepted: 12 June 2007 - Published: 1 August 2007

\begin{abstract}
GEM/POPs was developed to simulate the transport, deposition and partitioning of semi-volatile persistent organic pollutants (POPs) in the atmosphere within the framework of Canadian weather forecasting model GEM. In addition to the general processes such as anthropogenic emissions, atmosphere/water and atmosphere/soil exchanges, GEM/POPs incorporates a dynamic aerosol module to provide the aerosol surface areas for the semi-volatile POPs to partition between gaseous and particle phases and a mechanism for particle-bound POPs to be removed. Simulation results of three PCBs (28, 153 and 180) for the year 2000 indicate that the model captured the main features of global atmospheric PCBs when compared with observations from EMEP, IADN and Alert stations. The annual averaged concentrations and the fractionation of the three PCBs as a function of latitudes agreed reasonably well with observations. The impacts of atmospheric aerosols on the transports and partitioning of the three PCBs are reasonably simulated. The ratio of particulate to gaseous $\mathrm{PCBs}$ in the atmospheric column ranges from less than 0.1 for PCB28 to as high as 100 for PCB180, increasing from the warm lower latitudes to the cold high latitudes. Application of GEM/POPs in a study of the global transports and budgets of various PCBs accompanies this paper.
\end{abstract}

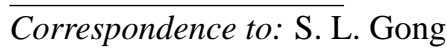

(sunling.gong@ec.gc.ca)

\section{Introduction}

Persistent organic pollutants (POPs) are organic chemical compounds and mixtures that include industrial chemicals like PCBs, pesticides like DDT and by-products of combustion like dioxins. Due to their resistance to degradation in the environment, POPs have long half-lives. Successive releases of these chemicals over time have resulted in continued accumulation in the global environment and posed a risk of causing adverse effects to human health and the environment. POPs released to the atmosphere with various physicochemical properties have substantial difference in their behaviours in the environment. As a result of the tendency of POPs to move from warmer to colder environment even the Arctic ecosystem is exposed to some POPs at levels of concern (Halsall, 2004; Hung et al., 2002). Due to POPs' ability to accumulate in various natural media, an evaluation of contamination by POPs requires a multi-compartment approach that includes atmosphere, soil and water.

There are two parallel modeling frameworks for studying environmental POPs. One type of them divides the globe or a specific region into a few climate zones (MacLeod, 2001; Toose et al., 2004; Wania and Mackay, 1995) with environmental compartments described in each zone. These models could be used to explore rates of global migration of POPs released in certain zonal bands to other latitudes and have been proven useful as a heuristic and policy tool

Published by Copernicus Publications on behalf of the European Geosciences Union. 
in demonstrating the "grasshopper" effect. However, these (multimedia) models are less suitable to predict the detailed spatial and short-term variability in the distribution of a compound. To overcome the limitation of box-type models, dynamical 3-D models have been developed to describe the atmospheric transport of POPs on both regional (Ma et al., 2003; van Jaarsveld et al., 1997), hemispheric (Gusev et al., 2005; Hansen et al., 2004) and global scales (Koziol and Pudykiewicz, 2001; Semeena and Lammel, 2005; Strand and Hov, 1996). These models include meteorological parameters such as wind speed, temperature and precipitation rate in finer spatial and temporal resolutions for more accurate transport, chemical reactions and removal processes of POPs. Species that have been simulated in these models include PCBs, DDTs and HCHs.

3-D dynamic models also make it possible to more realistically treat the phase partitioning of semi-volatile POPs between gaseous and particulate phases, which strongly influences the transformation, transport and fate of PCBs in the environment (Sahsuvar et al., 2003). The removal of a PCB from the atmosphere is very different if it is bound to particles than if it is in the gas phase. Thus it is essential to model PCB pathways in the atmosphere using a model that realistically simulates aerosols. Previous studies of POPs either deal with more volatile compounds such as $\mathrm{HCH}$ (Hexachlorocyclohexane) (Hansen et al., 2004; Koziol and Pudykiewicz, 2001) or use prescribed aerosol distributions for parameterizing partitioning for semi-volatile POPs (Gusev et al., 2005). The dynamic features of atmospheric aerosols were not realistically provided to properly simulate the semi-volatile POPs in the atmosphere. Semmna et al. (2006) studied the impact of climate and substance properties on the fate and atmospheric long-range transport of DDT and $\gamma-\mathrm{HCH}$ with an interactive aerosol module and portioning schemes. However, no substantial insights on the impact of the partitioning were discussed.

GEM/POPs is a 3-D global POPs transport model composed of two major components: (1) a multiscale air quality model (GEM-AQ) which includes a weather forecast model with on-line gas phase chemistry, an aerosol module CAM (Canadian Aerosol Module) and (2) a POPs exchange and partitioning module for atmosphere/water, atmosphere/soil exchanges and partitioning of POPs between gas and aerosols. This paper describes the modelling system and evaluates the performance with available observations of global PCBs. As a further application of GEM/POPs, the global transports and budgets of PCBs are simulated for three typical congeners that range from volatile (PCB28) to semivolatile (PCB153 and PCB180) species, which is presented in the companion paper (Huang et al., 2007).

\section{Model description}

\subsection{GEM-AQ}

GEM (Global Environmental Multiscale model) (Côté et al., 1998) was developed at MSC (Meteorological Service of Canada) for operational weather forecasting applications. GEM-AQ adds on a gas phase chemistry module (ADOM) (Venkatram et al., 1988) and an aerosol module (CAM) (Gong et al., 2003), which produces a 3-D global OH distribution for POP gas phase chemistry and a global aerosol surface area distribution for semi-volatile POP partitioning, respectively. Because of the inclusion of major atmospheric processes and types of aerosols in the CAM (Gong et al., 2003), the particle-bound removal rate of any semi-volatile POPs is treated as same as the particles.

\subsection{Atmospheric Processes of POPs}

In addition to the large scale transport of POPs by general circulation and turbulent mixing provided by GEM, GEM/POPs implemented the atmospheric processes of gas phase oxidation, exchanges between water/soil and atmosphere, and partitioning between particle and gas. The description of these processes is demonstrated with PCBs and the physiochemical properties of the 3 PCBs simulated in this study are listed in Table 1. To apply GEM/POPs to other POPs, the physiochemical properties, chemical reaction rate constants and emission fields of a specific POPs are needed.

\subsubsection{Oxidation}

It has been experimentally shown by several groups that the gas phase PCBs undergo homogeneous degradation by photolysis and reaction in the atmosphere dominantly with the hydroxyl $(\mathrm{OH})$ radicals but also with $\mathrm{NO}_{3}$ radicals and $\mathrm{O}_{3}$ (Anderson and Hites, 1996; Atkinson and Aschmann, 1985; Kwok et al., 1995). The OH reactions occur via addition to the biphenyl ring to replace chlorine atoms and to form various isomers of (PCB·OH):

$\mathrm{PCB}+\cdot \mathrm{OH} \rightarrow \mathrm{PCB} \cdot \mathrm{OH}$

and $\quad \partial C_{\mathrm{PCB}} / \partial t=-k_{\mathrm{OH}} \times C_{\mathrm{OH}} \times C_{\mathrm{PCB}}$

Assuming $[\mathrm{OH}]$ is constant, the integration gives

$\ln \left(C_{\mathrm{PCB}} / C_{\mathrm{PCB}, o}\right)=-k_{\mathrm{OH}} \times C_{\mathrm{OH}} \times t=-k_{\mathrm{OH}}^{\prime} \times t$

with $\quad \log k_{\mathrm{OH}}=-0.22 *(\# \mathrm{Cl})-11.25$

where, $C_{\mathrm{PCB}, o}$ is the initial PCB concentration, $t(\mathrm{~s})$ is time, $k_{\mathrm{OH}}\left(\mathrm{cm}^{3} /\right.$ molecule.s $)$ is the rate constant for PCB-OH reaction, $k_{\mathrm{OH}}^{\prime}\left(\mathrm{s}^{-1}\right)$ is the pseudo-first order rate constant, and $\# \mathrm{Cl}$ is the number of chlorine atoms on the PCB. Equation (4) is a linear regression fitted to the experimental data (Anderson and Hites, 1996). 
Table 1. Physicochemical properties of three PCB congeners and their temperature dependent parameters. $T=$ temperature $\left({ }^{\circ} \mathrm{K}\right), T_{0}=$ reference temperature $\left(298^{\circ} \mathrm{K}\right), R=$ gas constant.

\begin{tabular}{|c|c|c|c|c|c|c|}
\hline \multirow{2}{*}{ Property } & \multicolumn{5}{|c|}{ PCB Congener } & \multirow[t]{2}{*}{ References } \\
\hline & & Unit & PCB28 & PCB153 & PCB 180 & \\
\hline Henry's law constant: & $H_{0}$ & $\mathrm{~Pa} \mathrm{~m}^{3} \mathrm{~mol}^{-1}$ & 25.3 & 2.43 & 1.01 & (Achman et al., 1993) \\
\hline$H=H_{0} \exp \left(a\left(1 / T_{0}-1 / T\right)\right)$ & $a$ & $\mathrm{~K}$ & 2628 & 3416 & 3416 & \\
\hline \multicolumn{7}{|l|}{$H_{0}$ - Henry's law constant at the reference temperature $T_{0}$} \\
\hline Vapour pressure: & $P_{v}^{0}$ & $\mathrm{~Pa}$ & $3.13 \mathrm{E}-2$ & $6.71 \mathrm{E}-4$ & $1.29 \mathrm{E}-4$ & $\begin{array}{l}\text { (Falconer et al., 1995; } \\
\text { Harner and Bidleman, 1996) }\end{array}$ \\
\hline$P_{v}=10 * *(m / T+b)$ & $m$ & $\mathrm{~K}$ & -3935 & -4775 & -5042 & \\
\hline$T$ - temperature $\left({ }^{\circ} \mathrm{K}\right)$ & $b$ & & 11.70 & 12.85 & 13.03 & \\
\hline Degradation rate constants in air: & $K_{\mathrm{OH}}^{0}$ & $\mathrm{~cm}^{3}$ molecules ${ }^{-1} \mathrm{~s}^{-1}$ & $1.23 \mathrm{E}-12$ & $2.69 \mathrm{E}-13$ & $1.62 \mathrm{E}-13$ & (Sahsuvar, 1999) \\
\hline$K_{\mathrm{OH}}=K_{\mathrm{OH}}^{0} \exp a\left(1 / T_{0}-1 / T\right)$ & $a^{0}$ & $\mathrm{~K}$ & 800 & 1400 & 1400 & \\
\hline \multicolumn{7}{|l|}{$K_{\mathrm{OH}}^{0}$ is the value at the reference temperature $T_{0}$} \\
\hline Degradation rate constants in water: & $K_{\text {water }}$ & $\mathrm{s}^{-1}$ & $1.13 \mathrm{E}-8$ & $3.50 \mathrm{E}-9$ & $3.50 \mathrm{E}-9$ & (Mackay et al., 1992) \\
\hline Degradation rate constants in soil: & $K_{\text {soil }}$ & $\mathrm{s}^{-1}$ & $3.50 \mathrm{E}-9$ & $3.50 \mathrm{E}-9$ & $3.50 \mathrm{E}-9$ & \\
\hline \multicolumn{7}{|l|}{$\begin{array}{l}P_{v}-\text { vapour pressure } \\
a=-19.246 / T-0.9483 ; b=-529.05 / T+8.2995\end{array}$} \\
\hline $\begin{array}{l}\text { Octanol/water partitioning coefficient: } K_{o w}=K_{o a} * H / R T \\
H-\text { Henry's law constant }\end{array}$ & $K_{o w}^{0}$ & dimensionless & $1.14 \mathrm{E}+6$ & $5.37 \mathrm{E}+6$ & $1.19 \mathrm{E}+07$ & (Sahsuvar, 1999) \\
\hline Organic carbon/water partitioning coefficient: & $K_{o c w}^{0}$ & $\mathrm{~m}^{3} / \mathrm{kg}$ & $4.69 \mathrm{E}+2$ & $2.21 \mathrm{E}+3$ & $4.87 \mathrm{E}+3$ & $\begin{array}{l}\text { (Karickhoff, 1981; Mackay, 1991; } \\
\text { Schnoor, 1996) }\end{array}$ \\
\hline$K_{o c w}=0.411 * K_{o w}$ & & & & & & \\
\hline
\end{tabular}

\subsubsection{Atmosphere-water exchange}

Atmosphere-water exchange of PCBs was treated with a method by Liss and Slater (1974) characterized by mass transfer coefficients of $k_{W}$ (water side) and $k_{A}$ (air side). The dimensionless Henry's Law constant, $K_{A W}$, gives the ratio of the concentrations across the atmosphere-water interface with a flux:

$F=K_{T W}\left(C_{W}-C_{G} / K_{A W}\right)=K_{T A}\left(C_{W} \times K_{A W}-C_{G}\right)$

where overall mass transfer coefficients $K_{T W}$ (water-side, $\mathrm{s} \mathrm{m}^{-1}$ ) and $K_{T A}$ (air-side, $\mathrm{s} \mathrm{m}^{-1}$ ) are:

$$
\begin{aligned}
& 1 / K_{T W}=1 / k_{W}+1 /\left(k_{A} \times K_{A W}\right)=1 / k_{W}+R T /\left(H \times k_{A}\right) \\
& 1 / K_{T A}=1 / k_{A}+K_{A W} / k w=1 / k_{A}+H /\left(R T \times k_{W}\right)
\end{aligned}
$$

Assuming unsteady state, the Eq. (5) is solved to give the gas phase concentration of first model level as:

$$
C_{G}(t)=C_{W} \times K_{A W}+\left(C_{G O}-C_{W} \times K_{A W}\right) \exp \left(-K_{T A} \times \Delta t / h_{0}\right)
$$

where $C_{G O}$ is the initial atmosphere concentration and $h_{0}$ is the thickness of the first model layer. The water PCB concentration, $C_{W}$, is assumed constant for the integration time step $\Delta t$ but will change after receiving deposition from the atmosphere and transports in oceans. A detailed description of the dimensionless Henry's Law constant $\left(K_{A W}\right)$ and mass transfer coefficients $\left(k_{A}\right.$ and $\left.k_{W}\right)$ is given by (Sahsuvar et al., 2003) using the data from Table 1.

\subsubsection{Atmosphere-soil exchange}

An atmosphere-soil exchange model by Jury (Jury, 1989; Jury et al., 1983) was used for calculating the soil PCB fluxes to the atmosphere:

$$
F_{\text {net }}(0, t)=\left(C_{G, \text { soil }}-C_{G, \text { air }} \times K_{S A}\right) \sqrt{\frac{D_{E S}}{\pi \times t}}\left[1-\exp \left(\frac{-L^{2}}{4 D_{E S} \times t}\right)\right]
$$

where $C_{G \text {,soil }}$ and $C_{G \text {,air }}$ are the gaseous phase concentrations in soil and atmosphere, respectively, $K_{S A}$ (dimensionless) is the soil-atmosphere equilibrium coefficient, and $D_{E S}$ $\left(\mathrm{m}^{2} \mathrm{~s}^{-1}\right)$ is the effective diffusivity of the chemical (PCBs). The $D_{E S}$ term is derived from a series of equations and partitioning coefficients: $\mathrm{K}_{S A}$ and $K_{A W}$ (Sahsuvar et al., 2003). In the current GEM/POPs, the soil column with a depth of $L$ is divided into three superposed layers: $1 \mathrm{~cm}$ surface soil (z1), $3 \mathrm{~cm}$ second layer (z2) and $7 \mathrm{~cm}$ bottom layer (z3).

\subsubsection{Gas-aerosol partitioning}

The PCB amount partitioned between gas and aerosol phase depends on the aerosol surface area available for adsorption $\left(\mathrm{m}^{2}\right.$ aerosol $/ \mathrm{m}^{3}$ air) and the liquid-phase saturation vapour pressure of pure compound $(\mathrm{Pa})$. $\mathrm{PCB} /$ aerosol partitioning was simulated with the Junge-Pankow scheme (Junge, 1977; Pankow, 1987) as:

$\Phi=\frac{c \times \Theta}{P_{L}^{0}+c \times \Theta}=\frac{C_{P}}{C_{p}+C_{G}}$ 
Table 2. Soil concentrations of three PCBs in China (ng/g dry weight).

\begin{tabular}{lcccc}
\hline Locations & Coordinates & PCB28 & PCB153 & PCB180 \\
\hline Chongqing & $\mathrm{N} 29^{\circ} 33 \mathrm{E} 106^{\circ} 38$ & 24.3 & $\mathrm{ND}$ & $\mathrm{ND}$ \\
Wuhan & $\mathrm{N} 30^{\circ} 42 \mathrm{E} 114^{\circ} 36$ & 18.4 & 7.0 & 7.0 \\
Yichang & $\mathrm{N} 30^{\circ} 34 \mathrm{E} 111^{\circ} 27$ & 19.4 & $\mathrm{ND}$ & $\mathrm{ND}$ \\
Xian & $\mathrm{N} 33^{\circ} 84 \mathrm{E} 109^{\circ} 00$ & 23.1 & 4.7 & $\mathrm{ND}$ \\
Beijing & $\mathrm{N} 40^{\circ} 10 \mathrm{E} 117^{\circ} 18$ & 21.9 & 12.0 & 22.2 \\
Inner Mongolia & $\mathrm{N} 43^{\circ} 14 \mathrm{E} 122^{\circ} 14$ & 14.7 & $\mathrm{ND}$ & $\mathrm{ND}$ \\
\hline
\end{tabular}

ND: Not detectable

where,

$\Phi=$ fraction of semi-volatile organic compound adsorbed on aerosol particles $\left(C_{p}\right.$ and $C_{G}$ are the concentrations of particle-bound and gaseous PCBs)

$c=$ parameter that depends on the thermodynamics of the adsorption process and surface properties of the aerosol $(\mathrm{Pa} \mathrm{cm})$

$\Theta=$ aerosol surface area available for adsorption $\left(\mathrm{m}^{2}\right.$ aerosol $/ \mathrm{m}^{3}$ air $)$

$P_{L}^{0}=$ liquid-phase saturation vapour pressure of pure compound $(\mathrm{Pa})$

Junge's proposed value of the parameter $c$ is $17.2 \mathrm{Pacm}$ (Bidleman et al., 1998; Pankow, 1987). Within the GEM/POPs framework, the CAM provides aerosol surface areas $(\Theta)$ dynamically. In addition to the Junge-Pankow adsorption scheme adapted in this study, $K_{O A}$ (the octanol-air partition coefficient) based absorption model has also been used in predicting the phase partitioning of semi-volatile POPs (Finizio et al., 1997; Semeena et al., 2006), such as PCBs, DDT and $\gamma-\mathrm{HCH}$.

\subsubsection{Removal processes}

The particulate phase PCBs are removed along with the aerosols by wet and dry deposition which are given in details by Gong et al. (2003). The gas phase PCBs are destroyed by $\mathrm{OH}$ radical attack (see Sect. 2.2.1) and removed by precipitation scavenging, assuming to be in quasi-steady equilibrium with the rain drop. The net wet deposition flux, $F_{w}$, is then written as

$F_{w}=\left(-p / K_{A W}\right) \times C_{G}$

where $p$ is the precipitation rate, usually reported in $\mathrm{mm} / \mathrm{h}$ and $C_{G}$ is the gas phase PCB concentration.

\subsection{Ocean/lake transport module}

As previously discussed, an atmosphere-water exchange module needs the concentrations of POPs in the water provided by either an ocean/lake module or global observations. In GEM/POPs, an ocean tracer transport module is developed with prescribed global ocean currents from the UK
Ocean Circulation and Advanced Modelling Project (OCCAM) (de Cuevas, 1999) and with the French OPA tracer model (Foujols et al., 2000). With the 5-day mean oceanic currents from OCCAM as an input, the OPA tracer model computes the evolution of passive tracers and yields the 3-D distributions of POPs in world oceans. For regional simulation of POPs such as for the Great Lakes region in North America, a lake module is also needed to study the deposition and re-emission from lakes. Since this study deals with largely global transport features of PCBs, no lake module is included.

\subsection{Other processes}

In addition to the processes described above, there are other environmental compartments that POPs will be portioned in such as vegetation, ice and sediments (Malanichev et al., 2004). According to Malanichev et al. (2004), the emissions and accumulations of various PCBs from sea-water and vegetation take only a very small fraction of the total PCBs in the environmental media while the soil compartment is the dominant PCB sources in 1995. Consequently, the sea-ice and vegetation compartments are neglected in the current version of GEM/POPs in terms of the accumulation of PCB masses in these compartments. However, the deposition of POPs into these compartments is accounted for as the dry deposition scheme differentiates different land use categories.

\section{Input conditions}

\subsection{Meteorological data}

Simulation for the year 2000 was done with the re-analyzed meteorology from CMC (Canadian Meteorological Centre) updated every $24 \mathrm{~h}$ to drive the GEM. The model resolution was set at $2^{\circ} \times 2^{\circ}$ with an integration time step of $15 \mathrm{~min}$. The results shown in this paper were obtained after 2 years of spin-up runs prior to year 2000.

\subsection{Emission data}

The historical production of PCBs and chemical composition of various technical mixtures data for $22 \mathrm{PCB}$ congeners from 1930 to 2000 have been compiled from the literature (Breivik et al., 2002a). These data, along with assumptions on the trade between countries and regions, have been utilized to derive an estimate of the global historical consumption pattern. With a mass balance approach (Breivik et al., $2002 \mathrm{~b}$ ), estimates of the annual emissions of each of the 22 PCB congeners by country and year were obtained. For current simulation, using population density ( $\mathrm{Li}, 1996)$ as a surrogate, the national consumption or emission data were converted into globe $1^{\circ} \times 1^{\circ}$ emissions where the minimum, mean and maximum values were given, respectively. According to Wania and Daly (2002) the maximum emission 
PCB28

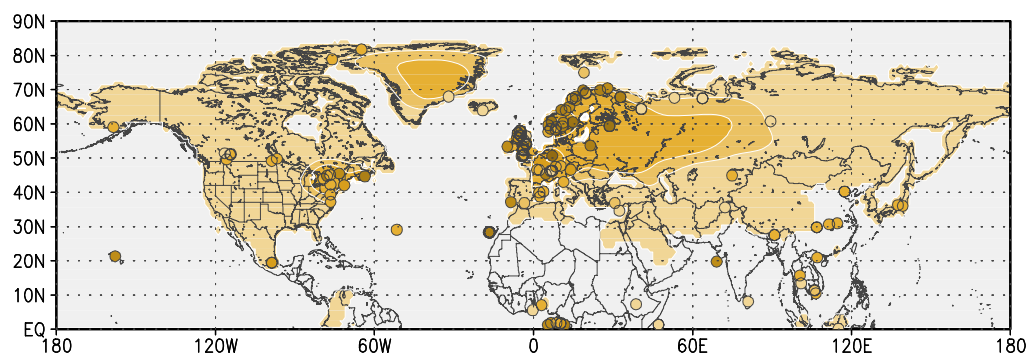

PCB153

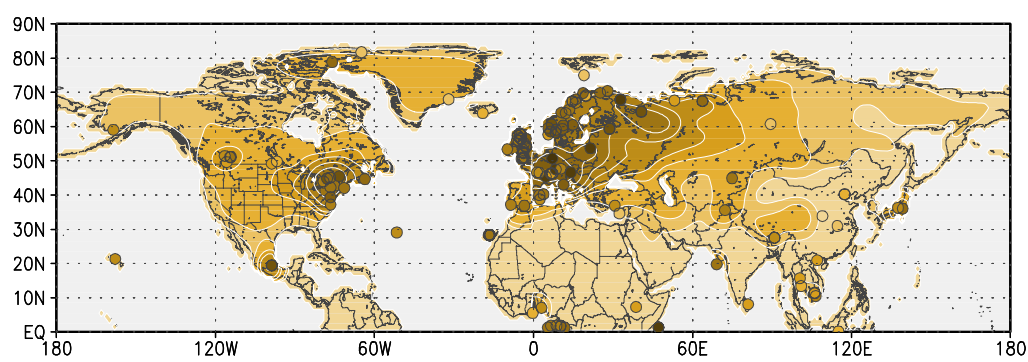

PCB180

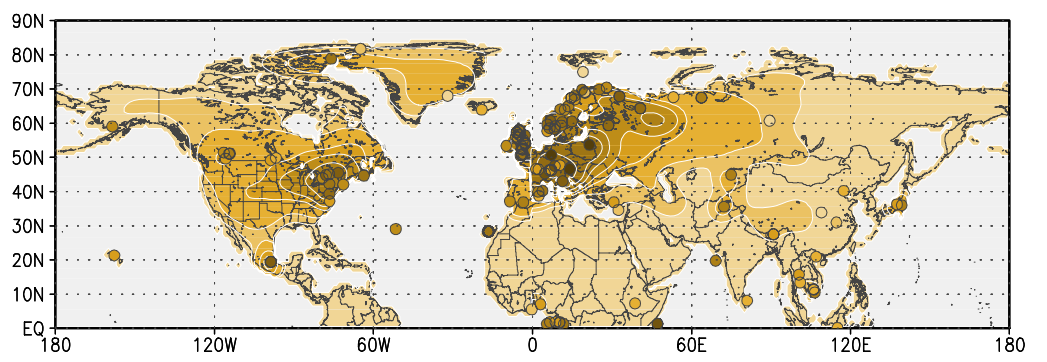

$\mathrm{ng} / \mathrm{g}$
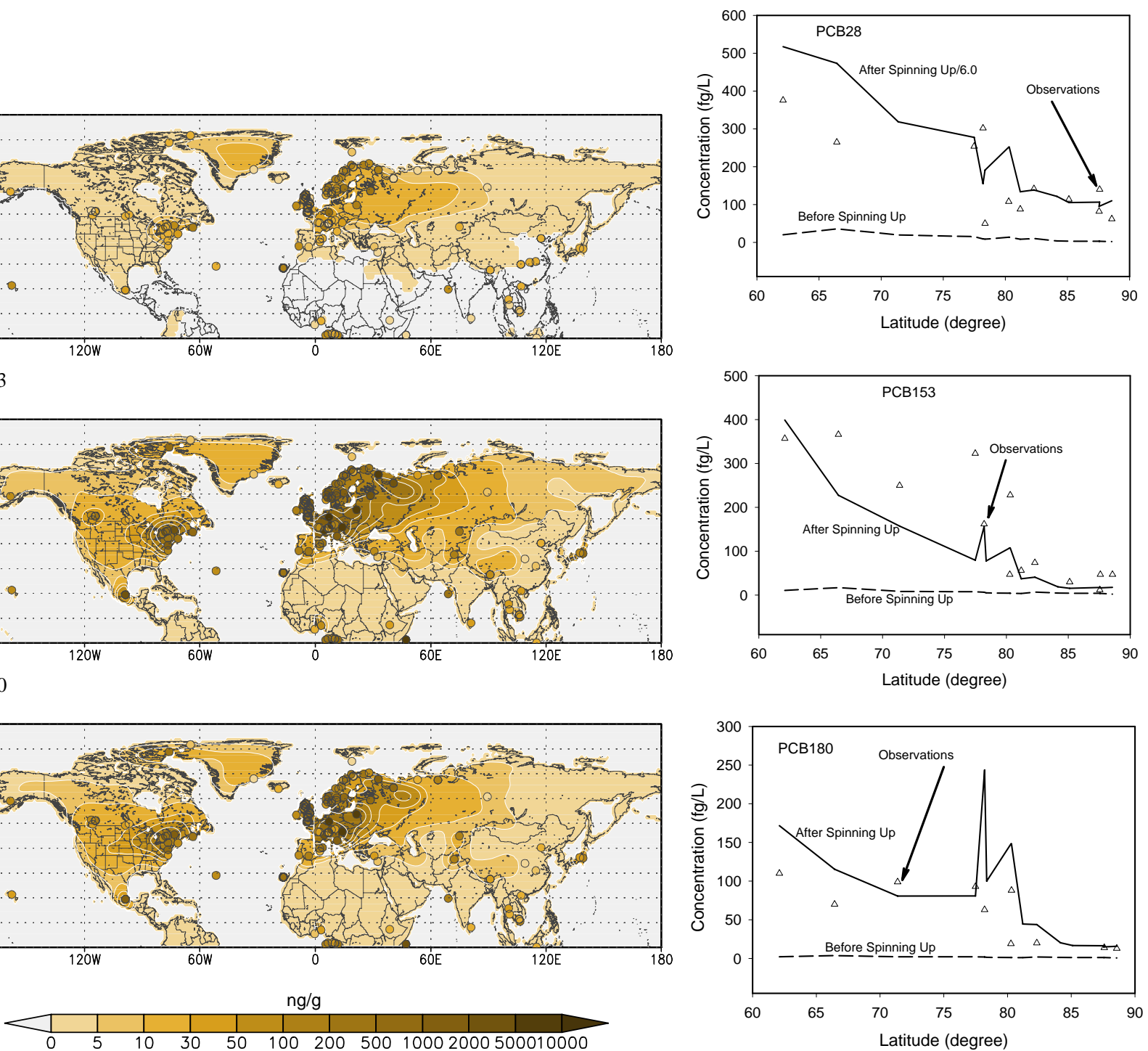

Fig. 1. (a) Assimilated three PCB soil concentrations from MSC-East hemispheric POP model outputs, soil concentrations (Meijer et al., 2003) and data from China (Table 2). The observed locations and concentrations are expressed as a lined circle filled with the same color scale as the contour plots. (b) Comparisons of the oceanic PCB concentrations used in the model after two years of spin-up simulations.

data is better to reflect the reality than mean and minimum emissions and is therefore used in this study.

\subsection{Initial soil and water concentrations}

Current systematic measurements of oceanic and soil PCBs are very limited to form an accurate picture of global distributions even though there exist some data of global soil concentrations (Meijer et al., 2003). Consequently, the model simulation results of both soil and oceanic concentrations of PCBs from the MSC-East hemispheric POP model (Gusev et al., 2005) were used to provide the required spatial distributions but the magnitudes of soil PCB concentrations differ substantially from the observations (Meijer et al., 2003). GEM/POPs combines the modeling and observational soil PCB concentrations by assimilating the modeled results with observations (Meijer et al., 2003) and soil concentration data in China (Table 2). The method is through a data-assimilation method (3-D-Var) to minimize the difference between the observations and the modeling results to achieve a more reasonable soil distribution than the original soil concentrations from the MSC-East model. Figure 1a shows the new assimilated PCB soil distributions that are used as the initial conditions for GEM/POPs. Superimposed on the figures are the measurement data. Compared to observations, these distributions are more realistic than the outputs from the original MSC-East model. 
Initial oceanic PCB concentrations were also evaluated against available observations. After two years of spin-up from the MSC-East model outputs, the sea water concentrations match the observations (Sobek and Gustafsson, 2004) very well for PCBs 156 and 180 (Fig. 1b) along the cruise ship track. Magnitudes and trends of these two PCBs along the latitude direction were reasonably reproduced. For PCB 28 , the latitude trend was produced but about 6 time overestimates for the oceanic surface concentration were produced (Fig. 1b).

\section{Simulation results of global PCBs}

\subsection{Comparisons with observations}

There are two types of monitoring data sets for global PCB distributions that are obtained from active and passive samplers, respectively. Active measurements use a high volume sampler that takes air through a filter. POPs' concentrations are then analyzed from the deposits on the filter. This type of technique has been used in a number of international, longterm monitoring programs such as NCP (Northern Contaminant Program), EMEP (Co-operative Programme for Monitoring and Evaluation of the Long-range Transmission of Air pollutants in Europe) and IADN (the Integrated Atmospheric Deposition Network). Trends and spatial distributions have been obtained from these sites. Recently, passive air sampler types have been developed and used in air monitoring of POPs (Harner et al., 2006). These samplers are small and relatively inexpensive and simple to deploy. Initial data set has been used to evaluate some modeling results (Shen et al., 2006). However, due the nature of the passive sampling, longer sampling time is needed than the active samplers and consequently temporal resolution of the data is rather coarse, i.e. one data per 2 to 7 months. Most of the data from the passive sampling network were not available before 2004 . Since this study was focused on year 2000, only data from the active sampling networks were used to compare with the modeling results.

Three major observational data sets of PCB atmosphere/particulate concentrations by active samplers were used in the comparison study: EMEP, IADN and Alert/Arctic, representing the European, the Great Lakes region (North America) and Arctic environments, respectively (Fig. 2a). The EMEP stations use very different sampling frequencies at various locations raging from one day/two days a week, one week a month, biweekly to monthly without differentiating gas and aerosol $\mathrm{PCBs}^{1}$. A monthly mean value of total PCBs for each station was given based on the sampling data by a high volume sampler. In IADN stations (Sun et al., 2006), the sampling frequency was 1 in 6 days before April 1994 and then switched to 1 in 12 days. Except for 1995, only gaseous PCBs were analyzed. The Alert station

\footnotetext{
${ }^{1}$ http://www.nilu.no/projects/CCC/onlinedata/pops/index.html
}

uses a high volume sampler with weekly integrated sampling and results in four weekly averaged data per month. Since the observed particle-bound concentrations are usually below method detection limits or too erratic to allow for a meaningful comparison to the modeled results, only gaseous PCBs were utilized for the study. Consequently, for the annual and monthly concentration comparisons, simulation results for total PCBs will be used at the EMEP stations while only gaseous PCBs at the IADN and Alert stations.

Figure $2 \mathrm{~b}$ shows the comparisons of model and observations in selected stations with annual averaged concentrations of both total and gaseous PCBs. A general agreement between modelled and observed PCBs is achieved with respect to the relative magnitudes of three different PCBs with the highest air concentration of PCB28 from 5 to $30 \mathrm{pg} \mathrm{m}^{-3}$ while the less volatile PCB153 and PCB180 have a smaller concentration ranging from around 1 to $0.1-0.5 \mathrm{pg} \mathrm{m}^{-3}$, respectively.

Total PCB28 simulated by GEM/POPs at EMEP stations agreed reasonably well with observations except at two Swedish sites: Aspvreten and Rörvik, where some overestimates were made. Two stations at IADN network also showed large over-estimates of gaseous PCB28: Burnt Island and Egbert. It is also noted that for the same station of Point Petre, the analysis done separately by the Canadian and American laboratories yielded very different results with the modeling results closer to the American analysis.

No PCB153 was analyzed at the American IADN sites. For EMEP and Canadian IADN sites, the comparison of both PCB153 and PCB180 is reasonable with two exceptions: Kosetice in Czech Republic and Burnt Island in Canada. The extreme high concentrations of PCB153 and 180 observed at the Kosetice site over the entire monitoring period (Fig. 3a) were not simulated. Compared to other European stations, this may imply the existence of some local PCB sources that were not accounted for in our emission inventories. On the contrary, the GEM/POPs predicted higher concentrations of gaseous PCB153 and PCB180 at Burnt Island than the IADN observations.

For the Arctic Alert, long records of PCBs (Hung et al., 2005a) have been obtained through the NCP (Northern Contaminant Program), indicating a decline trend for various PCBs (Hung et al., 2005b). The modeling results show a good agreement of the magnitudes of three modeled PCBs for year 2000 (Fig. 2b) with slightly overestimate of PCB28 and under-estimates of PCB153 and 180.

To further illustrate the seasonal variations of PCBs, monthly averaged PCB concentrations from GEM/POPs were also compared with observations for selected EMEP stations (Fig. 3a) and North American stations (Fig. 3b) for year 2000. Both total (solid black line) and gaseous (light gray lines) monthly mean PCBs from the GEM/POPs simulations are shown in the plots. For PCB28, the gaseous phase accounts for almost all of the mass with the overlap of gray and solid lines. Wherever possible, the measurement 
(a)

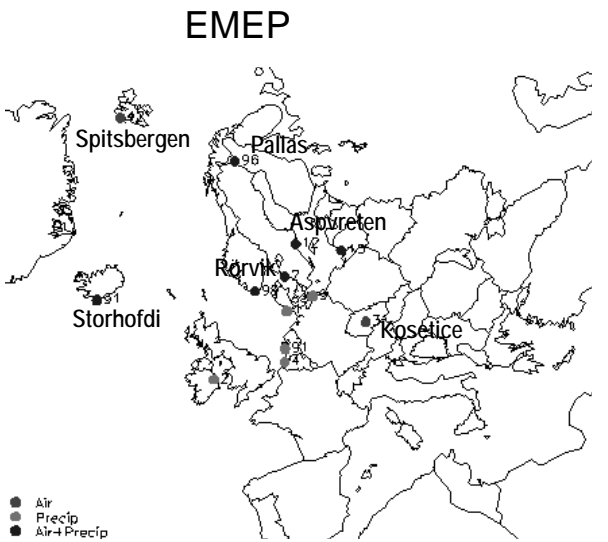

(b)
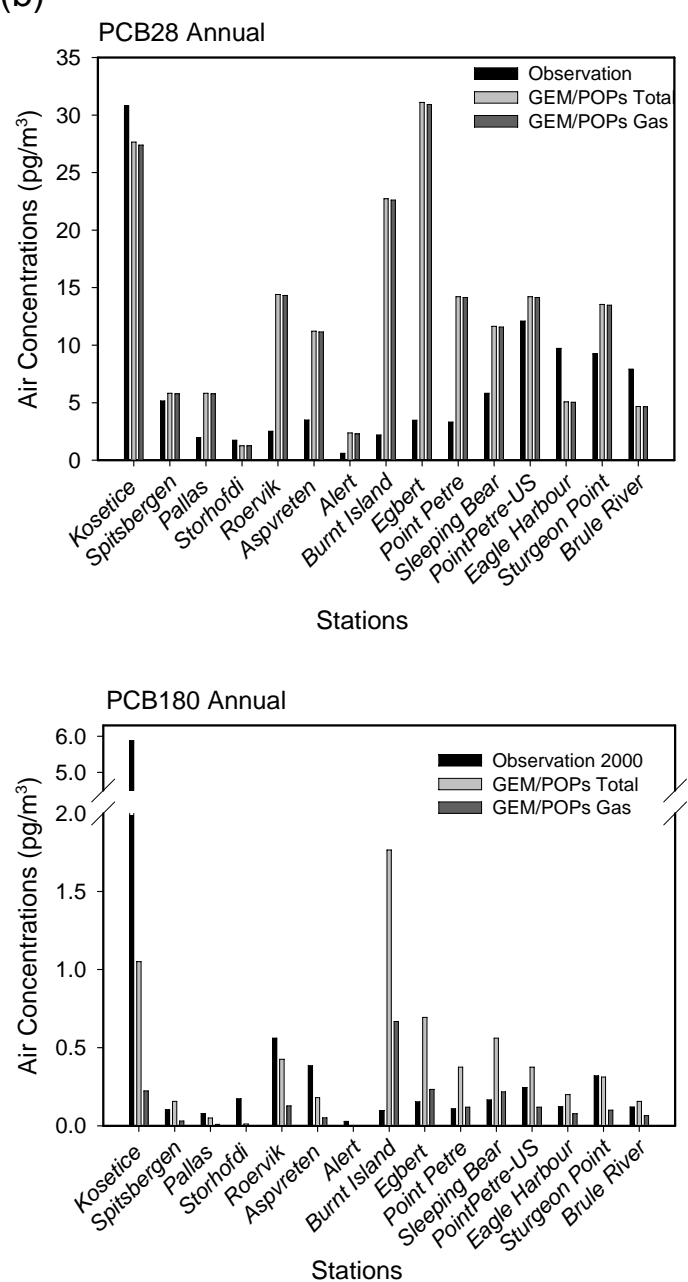

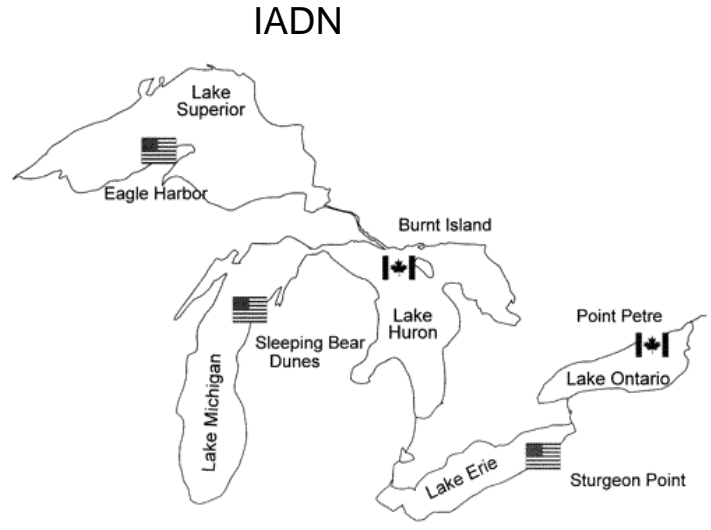

PCB153 Annual

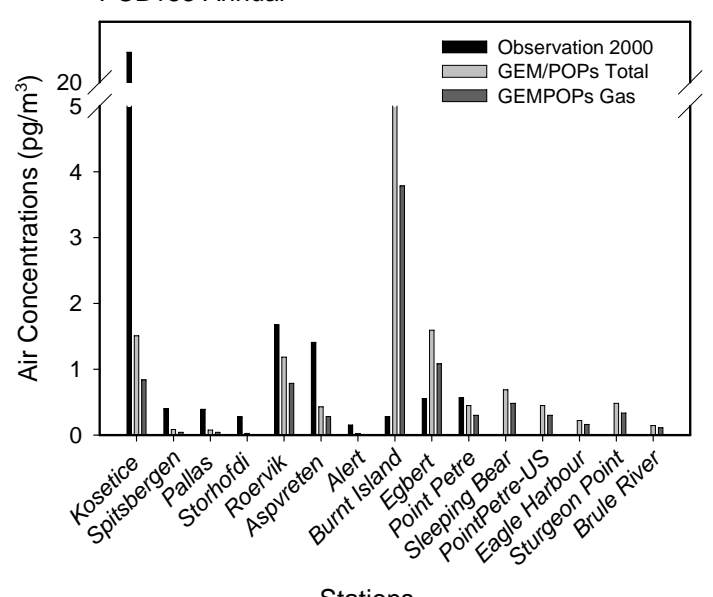

Stations

Site Information

\begin{tabular}{|lllll|}
\hline $\begin{array}{l}\text { Net } \\
\text { Work }\end{array}$ & Station Name & Country & Lat & Lon \\
\hline \multirow{5}{*}{ EMEP } & Kosetice & Czech & 49.58 & 15.08 \\
\cline { 2 - 5 } & & Republic & & \\
\cline { 2 - 5 } & Pallas/Särkijärvi & Finland & 68.00 & 24.12 \\
\cline { 2 - 5 } & Storhofdi & Iceland & 63.40 & 339.72 \\
\cline { 2 - 5 } & Spitsbergen & Norway & 78.90 & 11.88 \\
\cline { 2 - 5 } & Rörvik & Sweden & 57.42 & 11.93 \\
\cline { 2 - 5 } & Aspvreten & Sweden & 58.80 & 17.38 \\
\hline \multirow{5}{*}{ IADN } & Burnt Island & Canada & 45.81 & -82.95 \\
\cline { 2 - 5 } & Egbert & Canada & 44.23 & -79.78 \\
\cline { 2 - 5 } & Point Petre & Canada & 43.84 & -77.15 \\
\cline { 2 - 5 } & Sleeping Bear & US & 44.76 & -86.06 \\
\cline { 2 - 5 } & Eagle Harbour & US & 47.46 & -88.15 \\
\cline { 2 - 5 } & IIT- Chicago & US & 41.83 & -87.63 \\
\cline { 2 - 5 } & Sturgeon Point & US & 42.69 & -79.06 \\
\cline { 2 - 5 } & Brule River & US & -91.61 \\
\hline
\end{tabular}

Fig. 2. (a) Geographic locations of EMEP and IADN master stations. (b) Comparisons of observed and simulated annual averaged PCB28, 153 and 180 for 2000. Note: The PCB28 concentration from GEM/POPs was scaled down 6 times in the plot.

data for several years around 2000, e.g. between 1994-2004 for EMEP sites, 1992-2000 for Alert site and 1993-2003 for IADN, have been used to generate a vertical box to show the variation range of measured PCBs (gray box with whiskers).
It can be seen from Fig. 3a that for EMEP stations, most of the total predicted PCB153 and 180 are approaching the 10th percentile with some of them even within the 25th and 75th percentile range, indicating a reasonable agreement with the 
(a) EMEP Stations
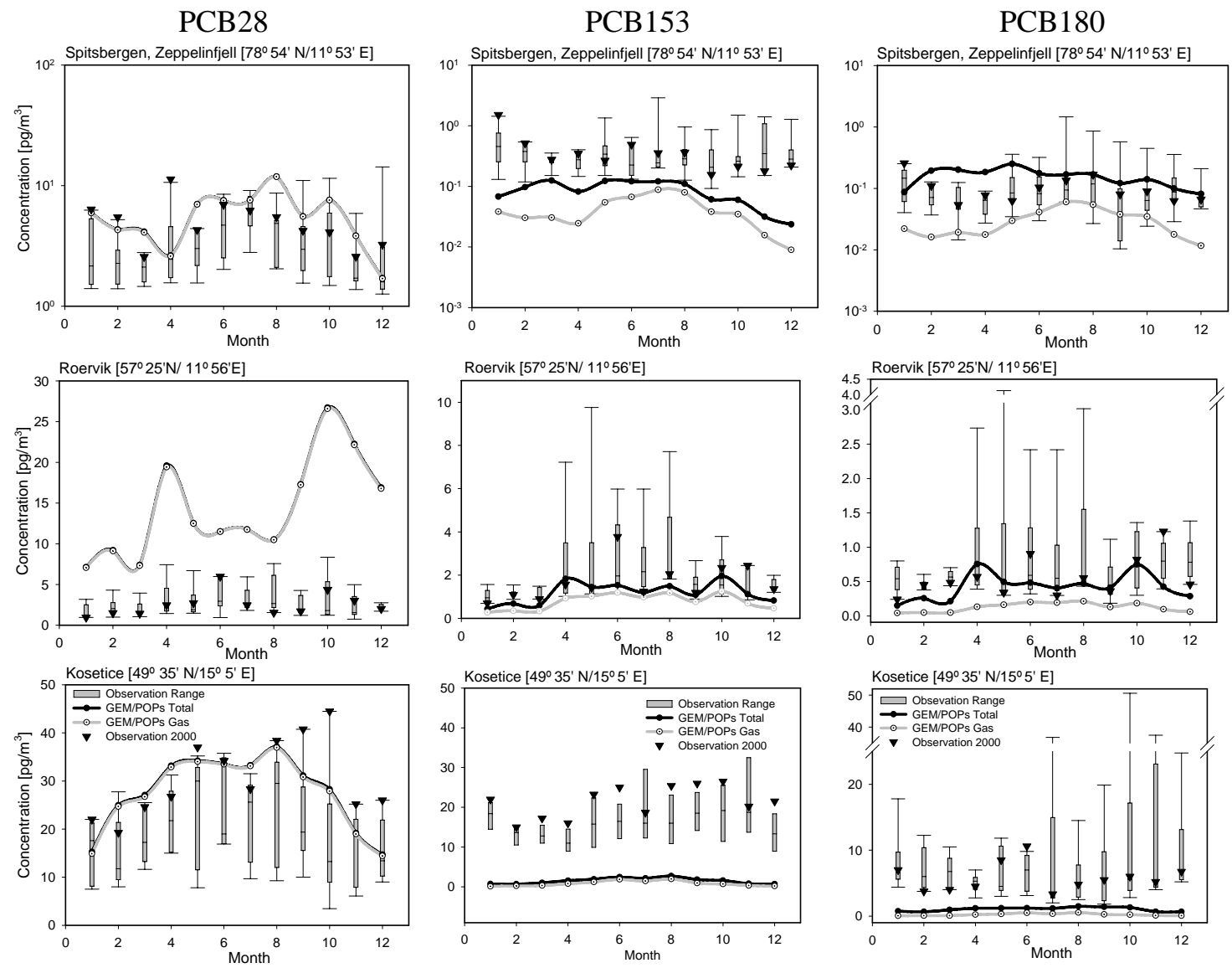

Fig. 3. Comparisons of modelled and observed three monthly PCBs for 2000 with the measurement range at (a) EMEP; (b) IADN; (c) Alert. The boundary of the box closest to zero indicates the 25 th percentile, a line within the box marks the median, and the boundary of the box farthest from zero indicates the 75th percentile. Whiskers (error bars) above and below the box indicate the 90th and 10th percentiles.

measured PCBs. It can also be inferred from the comparisons that there exists a trend of underestimates of heavy PCBs and a trend of over-estimate of lighter PCB28.

For IADN stations where gaseous PCBs were measured, overestimates of gaseous PCB28 concentrations at Point Petre, Burnt Island and Egbert stations were observed. However, a better agreement of PCB28 with American IADN sites was achieved (Fig. 3b). For PCB153 and 180, the comparison of gaseous phase concentrations reveals a very good agreement for most stations. The magnitudes and summer highs are well simulated except for the Burnt Island site. The PCBs at the Alert station were also reasonably simulated (Fig. 3c). The three PCBs simulated are in the right range of measured values with a summer peak from GEM/POPs at Alert for PCB28 that has not been observed.

Figure 4 shows the comparisons for the three PCBs between the modeling results from GEM/POPs and the observations averaged over IADN stations for the year 2000. The predictions for PCB180 are well within a factor of 2 from the observations. However, for PCB28 and PCB153, there are some over-estimates by GEM/POPs but majority of the results are within a factor of 3 . The over-estimate is especially evident for PCB153, indicting some systematic bias in the model.

There are many factors that influence model performance of PCBs when compared with observations. Initial soil concentrations used in the model constitute a large uncertainty to the modeling results. As legacy chemicals, PCBs have been used for more than a half century (Breivik et al., 2002a) and accumulations in soil have reached to such levels for some PCBs that may now serve as a dominant source (Huang et al., 2007) compared to the current anthropogenic emissions reported in the literatures (Breivik et al., 2002b) for year 2000. Nevertheless, measurements of global PCB soil concentrations are very limited (Meijer et al., 2003), mostly in Europe (Fig. 1a), resulting in large uncertainties in comput- 
(b) IADN Stations
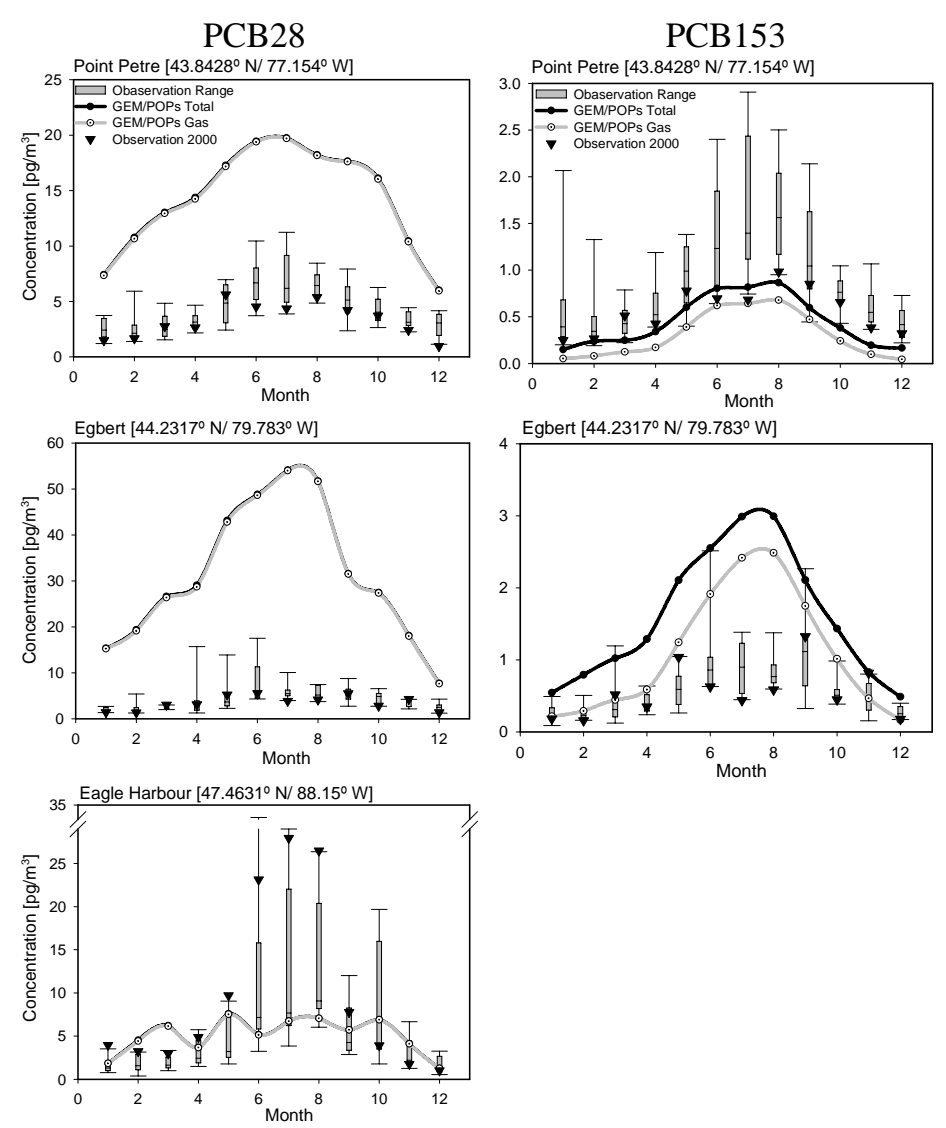

(c) Alert Station
PCB153

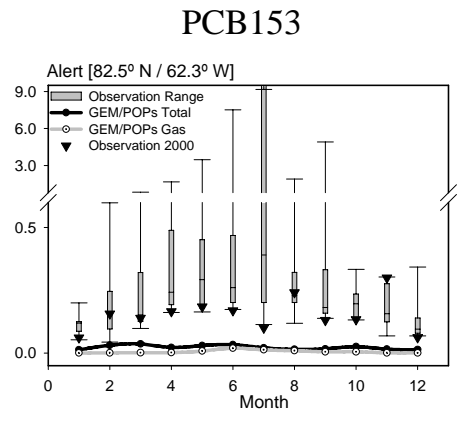

PCB28

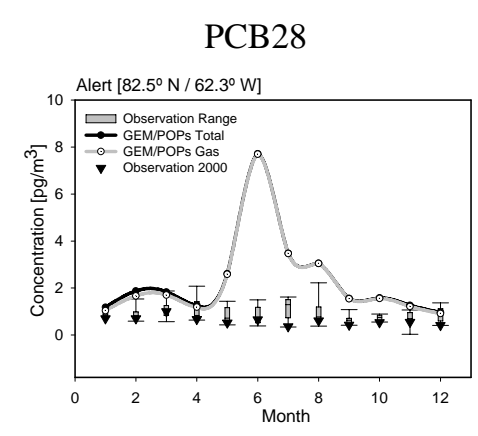

PCB180
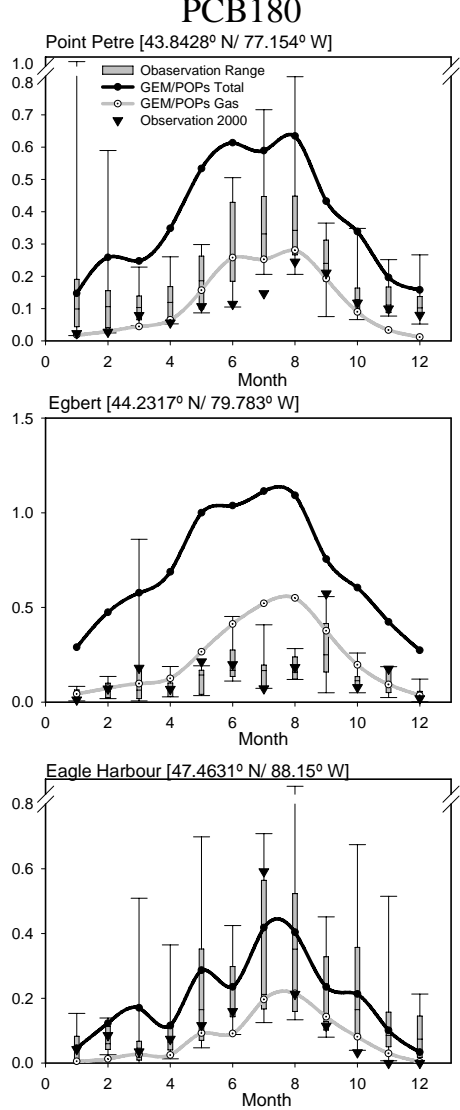

Fig. 3. Continued.

ing the soil-atmosphere exchange fluxes of PCBs over large part of the globe. The other dominant factor that affects the model performance is the uncertainty associated with the anthropogenic emission data. Besides, the PCB emissions have no seasonal variations and the grid values of each PCB are distributed from the total emission in a country by the population density. For large countries like Canada and US, this assumption may be subject to very large uncertainties.

\subsection{Fractionation of PCBs}

Though the global emissions of PCBs used in this study represent only order-of-magnitude estimates and the resulting model results should be treated with great caution (Breivik et al., 2002b), the congener compositions of PCB consumptions and emissions are more realistic. Comparison of the congener compositions from model with observations will further validate the model performance. Figure 5 shows the 
PCB28

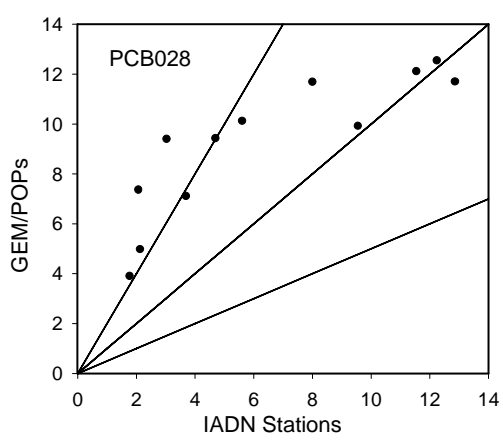

PCB153

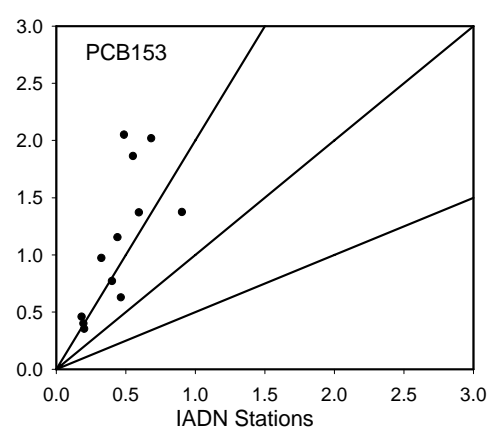

PCB180

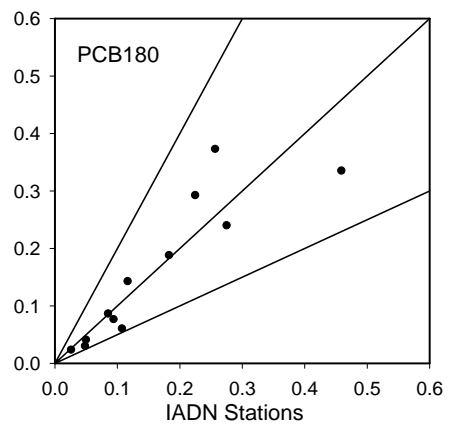

Fig. 4. Comparisons of three PCBs between the modeling results and the observations averaged over IADN stations for the year 2000.

(a)

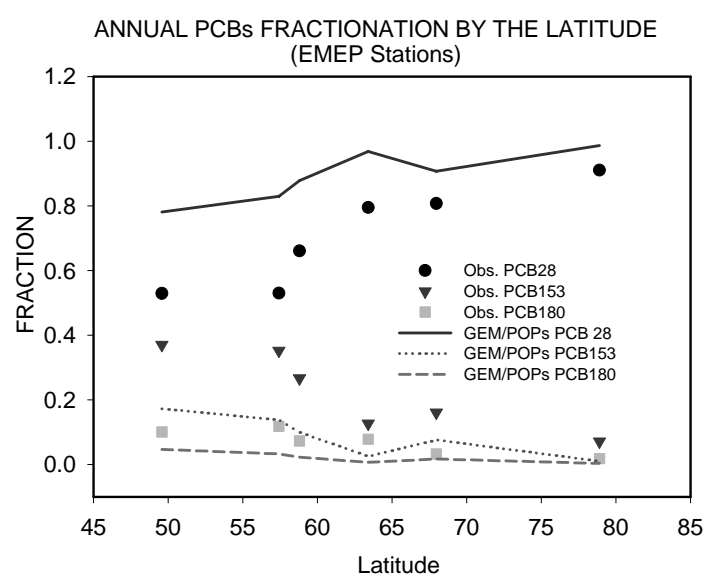

(b)

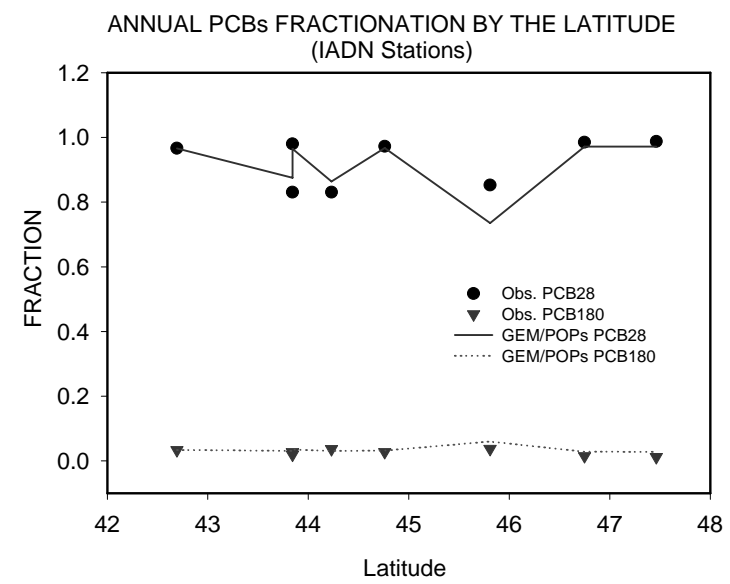

Fig. 5. Comparisons of PCB fractionations at (a) Europe and (b) North American stations.

fractions of three atmospheric PCBs as a function of latitude for both model simulation and observations in Europe (Fig. 5a) and the fractions of two PCBs in North America (Fig. 5b). PCB28 shows a slightly increasing trend from $50^{\circ} \mathrm{N}$ to $80^{\circ} \mathrm{N}$ in Europe for both model and observations with a slope of 0.015 and 0.007 , respectively while the heavier PCBs of 153 and 180 exhibit an opposite trend with latitude in Europe. The slopes for PCB153 and 180 are -0.005 and -0.001 for observations and -0.011 and -0.003 for model simulations. Similar trends of PCBs in soil have also been reported (Meijer et al., 2003).

For North America, only two measured PCBs (28 and 180) are available whose fractions among them are compared between observations and model simulations at IADN stations (Fig. 5b) with a very good agreement. Since the latitude span is only 6.5 degree for the IADN data, there are no distinct trends for both PCBs.

The relative abundance of three simulated atmospheric PCBs is well agreed with the observational data with a dominant fraction of PCB28 up to $95 \%$ and very small frac- tions of PCB153 and 180. This illustrates that the ability of the GEM/POPs to address the relative importance of various congeners in the atmosphere is rather robust.

\subsection{Impact of Aerosols on PCBs}

Figure 6 shows the simulation results of global atmospheric loadings (filled contours) of total PCB28 and 180 for spring of 2000 superimposed with the ratios (contour lines) of particulate to gas phase PCBs. Both PCBs follow the global distributions of their respective emission patterns with obvious inter-continental and polar transports while the absolute magnitude of atmospheric loading for PCB28 is much larger than that of PCB180. It can be seen from the plots that the impact of aerosols on the PCB global distribution becomes significant for heavier PCBs such as 180 . The ratio ranges around 0.1 for the volatile PCB28 and reaches as high as 100 for PCB 180 .

This is consistent with both theory and observations governing the behaviours of PCBs in the atmosphere. Due to 


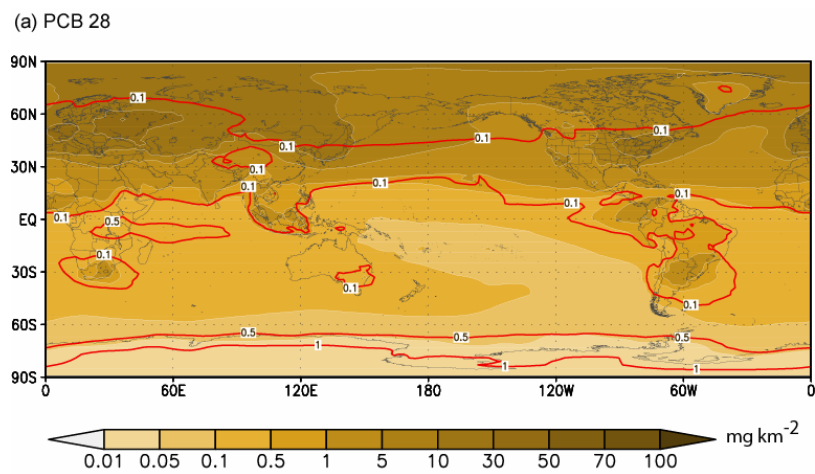

(b) PCB 180

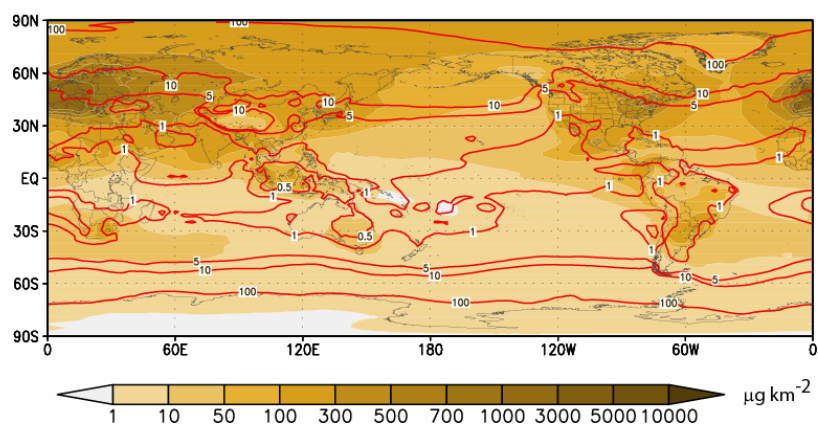

Fig. 6. Column loadings of the total atmospheric PCB28 and PCB180 (filled contours) and ratios of particulate to gaseous PCB28 and PCB180 (contour lines) in the atmosphere for spring of 2000.

their high vapour pressures, lighter PCBs (e.g. 28) are mostly found in the atmosphere without attaching to any particles. The transport and deposition processes are governed by the principles of gaseous molecules, which makes them easily engaged in long range transport. On the contrary, semivolatile PCBs are partitioned between atmosphere and particulates depending on the physicochemical properties of the PCBs and the environmental conditions. The dry and wet depositions of these particle-bound PCBs are much larger than those of gaseous phase PCBs. Consequently, heavier PCBs deposit back to the ground close to the source regions. The portion that engages in the long range transport is largely associated with particulate matters. For PCB180, the ratio of particulate to gaseous loading for spring varies from around 1.0 between $0^{\circ}-30^{\circ} \mathrm{N}$, to around 10 between $30^{\circ}-60^{\circ} \mathrm{N}$ and to around 100 between $60^{\circ}-90^{\circ} \mathrm{N}$, reflecting the impact of temperature on the partitioning of PCB180 to the aerosol particles. The seasonal variations of the ratios also reflect the impact of temperatures with smaller portions in the particulate phase in boreal summers than in winters.

Observations have also shown the similar behaviours of PCBs. For IADN stations where particle and gas phase PCBs were analyzed separately in 1995 using high-volume samplers, the ratios in winter and summer are 0.02 and 0.32 for PCB28, and 0.06 and 4.17 for PCB180 (Table 3). It is noted that these ratios were measured under surface con-
Table 3. Ratios of particulate to gaseous PCBs at three IADN stations.

\begin{tabular}{lllcc}
\hline Locations & Season & Month & PCB28 & PCB180 \\
\hline \multirow{4}{*}{ BBD Sleeping Bear Dunes } & Winter & DJF & 0.3224 & 4.1782 \\
& Spring & MAM & 0.0570 & 0.2240 \\
& Summer & JJA & 0.0963 & 0.0785 \\
& Fall & SON & 0.0568 & 0.0423 \\
\hline \multirow{4}{*}{ EGH Eagle Harbor } & Winter & DJF & 0.1817 & 0.7596 \\
& Spring & MAM & 0.1034 & 0.2802 \\
& Summer & JJA & 0.0581 & 0.1835 \\
& Fall & SON & 0.0523 & 0.0154 \\
\hline \multirow{3}{*}{ STP Sturgeon Point } & Winter & DJF & 0.1730 & 1.1782 \\
& Spring & MAM & 0.0439 & 0.5043 \\
& Summer & JJA & 0.0200 & 0.0695 \\
& Fall & SON & 0.0330 & 0.1220 \\
\hline
\end{tabular}

ditions while the model predictions were for the entire atmospheric column loadings where colder environments aloft favoured more partitioning of PCBs to the particulate phases. It is usually very difficult to accurately determine the ratios of particulate to gaseous phase PCBs. Mandalakis et al. (2002) pointed out that high amounts of PCBs may volatilize from fine particles during aerosols sampling using conventional high-volume samplers and found that average volatilization losses, determined by the diffusion denuder system, varied between 54 and 97\%, showing a strong dependence on partial pressure of individual PCB congeners and air temperature. Compared with IADN particulate fraction of PCBs (Table 3), GEM/POPs modeling results agreed with the general trends but over-estimated the ratios, which is consistent with the shortcoming for measuring particulate PCBs using high-volume samplers.

\section{Conclusions}

A scheme to simulate semi-volatile POPs with an active aerosol module, air/water, air/soil exchanges and POP/aerosol partition has been developed and applied in a global transport model to simulate PCBs in the atmosphere. A comparison of the simulation results with observations showed some degree of agreement but remained largely semi-quantitative considering the uncertainty factors in PCB emissions and soil reservoirs. A similar magnitude of air concentrations for three representative PCBs was predicted by the model for Europe and North America but the seasonal variations for some locations were not well resolved. On the other hands, the fractionation of three simulated PCBs in the atmosphere was well simulated for both Europe and North America when compared with observations, reflecting the usefulness of the model to simulate the relative abundance of various PCBs and their transports. 
It is found that lighter PCB congeners are more volatile, less partitioned to particle phase and reach higher concentrations in the air column. They can be readily transported long distances on the prevailing air currents and may remain in the atmosphere for a long period of time. Heavier PCBs are predicted to be relatively involatile, existing mainly in the particle-phase, and partitioning back to the surface at colder temperatures. The ratio of particle-phase to gas-phase PCB 28 is less than 0.1 while the ratio for PCB 180 ranges from 1.0 to 100 inversely proportional to temperatures.

CAN/POPs has been developed to study the behaviours of semi-volatile POPs in the atmosphere and the initial evaluation suggested that the model can reasonably simulate the transport and deposition of various PCBs. This lays the foundation for the assessment of the global cycles of various PCBs beginning with a companion paper on their intercontinental transport, deposition and budgets. Subsequent investigation of other POPs such as DDTs in the atmosphere will follow.

Acknowledgement. The authors wish to thank CFCAS (The Canadian Foundation for Climate and Atmospheric Sciences) for its partial finical support for this research through the NW AQ MAQNet Grant and T. Harner and M. Shoeib for their work in analyzing PCBs in Chinese soil samples. The authors also wish to thank S. Venkatesh for his careful reading of this manuscript and valuable suggestions.

Edited by: W. E. Asher

\section{References}

Achman, D. R., Hornbuckle, K. C., and Eisenreich, S. J.: Volatilization of Polychlorinated Biphenyls from Green Bay, Lake Michigan, Environ. Sci. Technol., 27, 75-87, 1993.

Anderson, P. N. and Hites, R. A.: OH Radical Reactions: The Major Removal Pathway for Polychlorinated Biphenyls from the Atmosphere, Environ. Sci. Technol., 30, 1756-1763, 1996.

Atkinson, R. and Aschmann, S. M.: Rate Constants for the GasPhase Reaction of Hydroxyl Radicals with Biphenyl and the Monochlorobiphenyls at 295K, Environ. Sci. Technol., 19, 462464, 1985.

Bidleman, T. F., Falconer, R. L., and Harner, T. (Eds.): Particle/Gas Distribution of Semivolatile Organic Compounds: Field and Laboratory Experiments with Filtration Samplers. Gas and Particle Partition Measurements of Atmospheric Organic Compounds, Gordon and Breach Publishers, Newark, New Jersey, 1998.

Breivik, K., Sweetman, A., Pacyna, J. M., and Jones, K. C.: Towards a global historical emission inventory for selected PCB congeners - a mass balance approach 1 . Global production and consumption, Sci. Total Environ., 290, 181-198, 2002a.

Breivik, K., Sweetman, A., Pacyna, J. M., and Jones, K. C.: Towards a global historical emission inventory for selected PCB congeners - a mass balance approach 2. Emissions, Sci. Total Environ., 290, 199-224, 2002b.

Côté, J., Gravel, S., Méthot, A., Patoine, A., Roch, M., and Staniforth, A.: The operational CMC-MRB Global Environmental
Multiscale (GEM) model: Part I - Design considerations and formulation, Mon. Wea. Rev., 126, 1373-1395, 1998.

de Cuevas, B. A., Webb, D. J., Coward, A. C., Richmond, C. S., and Rourke, E.: The UK Ocean Circulation and Advanced Modelling Project (OCCAM), in: High Performance Computing, Proceedings of HPCI Conference 1998, edited by: Allan, R. J., Guest, M. F., Simpson, A. D., Henty, D. S., and Nicole, D. A.,Plenum Press, Manchester, 325-335, 1999.

Falconer, R. L., Bidleman, T. F., and Cotham, W. E.: Preferential Sorption of Non-and-Mono-ortho-polychlorinated Biphenyls to Urban Aerosols, Environ. Sci. Technol., 29, 1666-1673, 1995.

Finizio, A., Mackay, D., Bidleman, T., and Harner, T.: Octanol-air partition coefficient as a predictor of partitioning of semi-volatile organic chemicals to aerosols, Atmos. Environ., 31, 2289-2296, 1997.

Foujols, M.-A., Levy, M., Aumont, O. and Madec, G.: OPA8.1 Tracer reference manual, Institut Pierre-Simon Laplace, 2000.

Gong, S. L., Barrie, L. A., Blanchet, J.-P., Salzen, K. v., Lohmann, U., Lesins, G., Spacek, L., Zhang, L. M., Girard, E., Lin, H., Leaitch, R., Leighton, H., Chylek, P., and Huang, P.: Canadian Aerosol Module: A size-segregated simulation of atmospheric aerosol processes for climate and air quality models 1. Module development, J. Geophys. Res., 108, 4007, doi:10.1029/2001JD002002, 2003.

Gusev, A., Mantseva, E., Shatalov, V., and Strukov, B.: Regional Multicompartment Model MSCE-POP, EMEP/MSC-E Technical Report 5/2005, Moscow, 2005..

Halsall, C. J.: Investigating the occurence of pesistent organic pollutants (POPs) in the Arctic: Their atmospheric behaviour and interaction with the seasonal snow pack, Env. Poll., 128, 163175, 2004.

Hansen, K. M., Christensen, J. H., Brandt, J., Frohn, L. M., and Geels, C.: Modelling atmospheric transport persistent organic pollutants in Northern Hemisphere with a 3-D dynamical model: DEHM-POP, Atmos. Chem. Phys., 4, 1125-1137, 2004, http://www.atmos-chem-phys.net/4/1125/2004/.

Harner, T. and Bidleman, T. F.: Measurement of Octanol-Air Partition Coefficients for Polychlorinated Biphenyls, J. Chem. Eng. Data, 41, 895-899, 1996.

Harner, T. and Bidleman, T. F.: Octanol-Air Partition Coefficient for Describing Particle/Gas Partitioning of Aromatic Compounds in Urban Air, Environ. Sci. Technol., 32, 1494-1502, 1998.

Harner, T., Pozo, K., Gouin, T., Macdonald, A.-M., Hung, H., Cainey, J., and Peters, A.: Global pilot study for persistent organic pollutants (POPs) using PUF disk passive air samplers, Environ. Poll., 144, 445-452 2006.

Huang, P., Gong, S. L., Zhao, T. L., Neary, L., and Barrie, L. A.: GEM/POPs: a global 3-D dynamic model for semi-volatile persistent organic pollutants - Part 2: Global transports and budgets of PCBs, Atmos. Chem. Phys., 7, 4015-4025, 2007, http://www.atmos-chem-phys.net/7/4015/2007/.

Hung, H., Blanchard, P., Halsall, C. J., Bidleman, T. F., Stern, G. A., Fellin, P., Muir, D. C. G., Barrie, L. A., Jantunen, L. M., Helm, P. A., Ma, J., and Konoplev, A.: Temporal and spatial variabilities of atmospheric polychlorinated biphenyls (PCBs), organochlorine (OC) pesticides and polycyclic aromatic hydrocarbons (PAHs) in the Canadian Arctic: Results from a decade of monitoring, Sci. Total Environ., 342, 119-144, 2005a.

Hung, H., Halsall, C. J., Blanchard, P., Li, H. H., Fellin, P., Stern, G. 
and Rosenberg, B.: Temporal trends of organochlorine pesticides in the Canadian Arctic atmosphere, Env. Sci. Technol., 36, 862$868,2002$.

Hung, H., Lee, S. C., Wania, F., Blanchard, P., and Brice, K.: Measuring and simulating atmospheric concentration trends of polychlorinated biphenyls in the Northern Hemisphere, Atmos. Environ., 39, 6502-6512, 2005b.

Junge, C. E. (Ed.): Fate of Pollutants in the Air and Water Environments, 1. J. Wiley, New York, 7-26, 1977.

Jury, W. A.: Volatilization From soil, in:Vadose Zone Modeling of Organic Pollutants, 3rd ed., edited by: Hern, S. C. and Melancon, S. M., Lewis Publishers Inc., Michigan, 1989.

Jury, W. A., Spencer, W. F., and Farmer, W. J.: Behavior Assessment Model for Trace Organics in Soil: I.Model Description, J. Environ. Qual., 12, 558-564, 1983.

Karickhoff, S. W.: Semi-Empirical Estimation of Sorption of Hydrophobic Pollutants on Natural Sediments and Soils, Chemosphere, 10, 833-846, 1981.

Koziol, A. S. and Pudykiewicz, J. A.: Global-scale environmental transport of persistent organic pollutants, Chemosphere, 45, 1181-1200, 2001.

Kwok, E. S. C., Atkinson, R., and Arey, J.: Rate Constants for the Gas_Phase Reactions of the OH Radical with Dichlorobiphenyls, 1-Chlorodibenzo-p-dioxin, 1,2-Dimethoxybenzene, and Diphenyl Ether: Estimation of $\mathrm{OH}$ Radical Reaction Rate Constants for PCBs, PCDDs, and PCDFs, Environ. Sci. Technol., 29, 1591-1598, 1995.

Li, Y.-F.: Global Population Distribution Database, A Report to the United Nations Environment Programme, under UNEP SubProject FP/1205-95-12, 1996.

Liss, P. S. and Slater, P. G.: Flux of Gases across the Air-Sea Interface, Nature, 247, 181-197, 1974.

Ma, J., Daggupaty, S., Harner, T., and Li, Y.-F.: Impacts of Lindane usage in the Canadian prairies on the Great Lakes ecosystem, 1. Coupled atmospheric transport model and modeled concentrations in air and soil, Environ. Sci. Technol., 37, 3774-3781, 2003.

Mackay, D.: Multimedia Environmental Models, The Fugacity Approach, Lewis Publishers, 1991.

Mackay, D., Shiu, W. Y., and Ma, K. C.: Illustrated Handbook of Physical-Chemical Properties and Environmental Fate for Organic Chemicals, I. Lewis Publishers Inc., Michigan, 1992.

MacLeod, M., Woodfine, D., Mackay, D., McKone, T., Bennett, D., and Maddalena, R.: BETR North America: A Regionally Segmented Multimedia Contaminant Fate Model for North America, Environ. Sci. Pollut. Res., 8, 156-163, 2001.

Malanichev, A., Mantseva, E., Shatalov, V., Strukov, B., and Vulykh, N.: Numerical evaluation of the PCB transport over the Northern Hemisphere, Environ. Poll., 128, 279-289, 2004.

Mandalakis, M. and Stephanou, E. G.: Polychlorinated biphenyls associated with fine particles (pm2.5) in the urban environment of Chile: concentration levels, and sampling volatilization losses, Environ. Toxicol. Chem., 21, 2270-2275, 2002.

Meijer, S. N., Ockenden, W. A., Sweetman, A. J., Breivik, K., Grimalt, J. O. and Jones, K. C.: Global distribution and budget of PCBs and HCB in background surface soils: implications for sources and environmental processes, Environ. Sci. Technol., 37, 667-672, 2003.
Pankow, J. F.: Review and Comparative Analysis of the Theories on Partitioning Between the Gas and Aerosol Particulate Phases in the Atmosphere, Atmos. Environ., 21, 2275-2283, 1987.

Sahsuvar, L.: Modelling Physical Chemical Properties and Pathways of Polychlorinated Biphenyls in the Atmosphere, MSc Thesis, York University, Toronto, 140 pp., 1999.

Sahsuvar, L., Helm, P. A., Jantunen, L. M., and Bidleman, T. F.: Henry's law constants for alpha-, beta-, and gammahexachlorocyclohexanes $(\mathrm{HCHs})$ as a function of temperature and revised estimates of gas exchange in Arctic regions, Atmos. Environ., 37, 983-992, 2003.

Schnoor, J. L.: Environmental Modeling. Fate and Transport of Pollutants in Water, Air, and Soil, Environmental Science and Technology, John Wiley \& Sons, Inc., New York, 1996.

Semeena, V. S., Feichter, J., and Lammel, G.: Impact of the regional climate and substance properties on the fate and atmospheric long-range transport of persistent organic pollutants - exampled of DDT and $\gamma$-HCH, Atmos. Chem. Phys., 6, 1231-1248, 2006, http://www.atmos-chem-phys.net/6/1231/2006/.

Semeena, V. S. and Lammel, G.: The significance of the grasshopper effect on the atmospheric distribution of president organic substances, Geophys. Res. Lett., 32, L07804, doi:10.1029/2004GL022229, 2005.

Shen, L., Wania, F., Lei, Y. D., Teixeira, C., Muir, D. C. G., and Xiao, H.: Polychlorinated biphenyls and polybrominated diphenyl ethers in the North American atmosphere, Environ. Poll., 144, 434-444, 2006.

Sobek, A. and Gustafsson, O.: Latitudinal fractionation of polychlorinated biphenyls in surface seawater along a 62 degrees $\mathrm{N}$ 89 degrees $\mathrm{N}$ transect from the southern Norwegian Sea to the North Pole area, Environ. Sci. Technol., 38, 2746-2751, 2004.

Strand, A. and Hov, Ø.: A model strategy for the simulation of chlorinated hydrocarbon distributions in the global environment, Water Air Soil Poll., 86, 283-316, 1996.

Sun, P., Backus, S., Blanchard, P., and Hites, R. A.: Annual variation of polycyclic aromatic hydrocarbon concentrations in precipitation collected near the Great Lakes, Environ. Sci. Technol., 40, 696-701, 2006.

Toose, L., Woodfine, D. G., MacLeod, M., Mackay, D., and Gouin, J.: BETR-World: a geographically explicit model of chemical fate: application to transport of alpha-HCH to the Arctic, Environ. Poll., 128, 223-240, 2004.

van Jaarsveld, J. A., van Pul, W. A. J., and de Leeuw, F. A. A. M.: Modelling transport and deposition of persistent organic pollutants in the European region, Atmos. Env., 31, 1011-1024, 1997.

Venkatram, A., Karamchandani, P. K., and Misra, P. K.: Testing a comprehensive acid deposition model, Atmos. Environ., 22, 737-747, 1988.

Wania, F. and Daly, G. L.: Estimating the contribution of degradation in air and deposition to the deep sea to the global loss of PCBs, Atmos. Environ., 36, 5581-5593, 2002.

Wania, F. and Mackay, D.: A global distribution model for persistent organic chemicals, Sci. Total Environ., 160/161, 211-232, 1995. 